\title{
SMART E-TESTING: FUTURE TREND OF E-LEARNING OR GENTLE DEVIATION
}

\author{
Marjan Krašna, Tomaž Bratina \\ University of Maribor, Slovenia \\ E-mail: marjan.krasna@uni-mb.si, tomaz.bratina@uni-mb.si \\ Branko Kaučič \\ University of Ljubljana, Slovenia \\ E-mail: branko.kaucic@pef.uni-lj.si
}

\begin{abstract}
A decade of experience with e-learning material production gives significant trends overview. From the perspective of ICT evolution this means very long time. E-learning is always closely coupled to ICT but with the distinction - it always lags behind the advancement in ICT. Among many unknown issues one thing is certain - e-learning permanently changes. From the past experiences prediction of immediate future e-learning is possible but the prediction for longer time is less accurate. In the article chronological e-learning achievements and their connections are presented in order to give an overview of trends in e-learning in Slovenia. But despite of the detailed past knowledge fundamental prediction error of e-learning future developments was made. Today's hot topics are not better e-learning materials, not even broad application of interactive boards but e-testing. Possible immediate future of e-learning is therefore application of intelligent e-testing systems. Intelligent computer assisted testing (CAT) is not the new topic in e-learning. It is object of many researches but it is not suitable for teachers. It is way too complicated for teachers to apply it successfully in their work. E-learning development process for intelligent computer assisted test production that suits teachers' competences is prepared and explained in the article.
\end{abstract}

Key words: distance education, electronic testing, learning management system, knowledge assessment.

\section{Introduction}

E-learning has started in our country at the turn of the century. First e-learning materials were produced for study course Multimedia. Beginning with static web pages oriented to low bandwidth internet connection process gradually included more and more high quality multimedia elements and finishes with learning management system (LMS). But now new trends are considered to produce low-computer power and electricity efficient e-learning materials suitable for portable devices (BBC, 2012).

Today almost every teacher knows what multimedia is and how to apply it in the classroom. Multimedia has influenced many new e-learning materials development and transfer of the knowledge to the primary school. Looking back to the beginning of e-learning several time periods can be identified in Slovenian teachers' education:

- Period 1 - Initial research $(1996-1998)$

- Period 2 - The beginning $(1998-2002)$

- Period 3 - Maturity $(2002-2006)$

- Period 4 - Restructuring (2006-2010)

- Period 5 - Mainstream (2010 - today) 
PROBLEMS

OF EDUCATION

IN THE $21^{\text {st }}$ CENTURY

Volume 46, 2012

Trends overview shows students want better e-learning materials but the teachers turn into different direction - e-tests. E-testing in education is not new but requires some training. Free authoring tools enable simple tests preparation. More elaborate e-testing requires different development process which is beyond the competences of Slovenia's teachers. But in the article simpler process is going to be explained that have a potential to introduce better e-testing to lower levels of education (primary and secondary schools).

\section{Programmed Learning Paradigm in E-learning Material Development}

During the last decade many e-learning materials development projects were conducted in Slovenia. During this time new ideas emerged and old ideas were reinvented in new or more aesthetically pleased manner (i.e. Apple iBook). Research has shown that Web 2.0 in "modern education" is not mandatory for success of e-learning materials. Some old fashioned e-resources are still highly regarded and frequently used by students (Repnik, Krašna, \& Kaučič, 2012).

Implementation of a digital augmented, blended, assisted, collaborative, etc. learning requires a significant teachers' effort. Teachers should use contemporary approaches and technology, and prepare high quality visually appealing e-learning materials. It is expected that teachers should produce such learning materials for their needs. This is not true though. Teachers are incapable to follow the advancement in technology and its effective use. Computer technology in education is therefore mostly used for writing text and web browsing (Gerlič, Bratina, Veček, \& Pungartnik, 2011).

In the last few years LMSs are used in Slovenia's educational institutions. Workshops for their use were organized as in-house training or as LLL (Lifelong Learning) activities. Teachers and students are now reasonably familiar with LMSs. But in general LMSs are still mostly used for learning material distribution, messaging and data warehouse for students' assignments. An E-learning material produced with programmed learning paradigm receives higher students' appreciations but requires e-testing phase after each topic. In order to better utilize LMS's abilities several demands for additional training from lecturers were expressed recently. According to the students' demands expectation was that teachers would like to upgrade their learning materials or use advanced types of communication. Surprisingly most desirable demand was how to efficiently use e-testing.

\section{Computer Based Testing and Computer Adaptive Tests}

Computer based testing (CBT) (Parshall, Spray, Kalohn, \& Davey, 2002) and technologybased assessment (TBA) can be fast (but processor intensive). Students get feedback as soon as they finish the test (i.e. submit all answers to the system). Traditional e-tests enable students to answer questions in random order until they submit results or run out of time.

It is evident that all tests are not equally suitable in every situation. With the increase of complexity potential problems increase. Positive or negative question type can be used to examine the knowledge. Positive questions are usually easier for examinee than negative. The questions therefore are:

- How to explain the situation where students answer positive question type and not negative?

- What should be graded: the knowledge or understanding of question?

Traditional e-tests are linear with the fixed or random questions. It is easy for teachers to assess student's knowledge and (transferable) skills and wider competencies in different situations. Students are individuals and process information in different ways to learn a given domain topic area (Costello \& Mundy, 2009) therefore in the process of knowledge evaluation teachers apply adapted assessments principle. 
Adaptability is the ability to "tailor the difficulty level of each question based on the correctness of the previously answered question" (Basu, Cheng, Prasad, \& Rao, 2007). Adaptive techniques were developed for local systems before the advent of WWW (Barra, Iannaccone, Palmieri, \& Scarano, 2002). First computerized adaptive testing was proposed in 1980 (Lord, 1980), and lately adaptive technology is more and more used also in CBT. In the literature different naming and abbreviations can be found for adaptive CBT, such as computeradaptive assessment (CAA) and computer adaptive testing (CAT). Adaptive e-tests are e-tests in which the number and sequence of test items are adjusted during the test in response to the performance of the person being tested (Chua Abdullah \& Cooley, 2002)(Chen \& Wang, 2010). Such tests are:

- Quicker to administer,

- Reduce costs in administering tests,

- Can significantly reduce the number of questions (even for 50\%) (Cheng, Rodrigez, \& Basu, 2009),

- Are student friendly, and

- Not less precise than non-adaptive tests (Basu, Cheng, Prasad, \& Rao, 2007) (Chua Abdullah \& Cooley, 2002).

Their main disadvantage is that questions paths are modeled with probabilistic functions (Guzmán \& Conejo, 2005). In addition, they still do not solve concerns as in CBT: cost of technology, technology malfunction, administrator training, and student's computer skill, but these concerns are usually easy to deal with. The theories behind adaptive e-tests are Student Model (SM) (Chen \& Zhang, 2008) of modeling student behavior and characteristics, and Item Response Theory (IRT) (Chen \& Wang, 2010)(Guzmán \& Conejo, 2005)(Chen \& Zhang, 2008) which is a robust well-founded psychometric theory in education assessment. The latter is responsible for estimating student knowledge, determining the next question that must be posed at each moment, and deciding test finalization (Guzmán \& Conejo, 2005). Some authors name combination of SM and IRT as Computer Adaptive Test Theory (CAT theory) (Danieliené \& Telešius, 2008).

From ICT point of view imitation of teachers in oral exams in CAT is done with methods of artificial intelligence (AI) and expert educational systems (Gerlič, 2000). Since not a lot of systems are developed and generally used, adaptive assessment is still "an innovative, online form of assessment in which items are presented in a sequence that is dependent on the correctness of the examinee's response to the preceding item"(Basu, Cheng, Prasad, \& Rao, 2007). Some products that reader can find in the literature are: system called Test ++ that bases on playing game methodology (Barra, Iannaccone, Palmieri, \& Scarano, 2002), SIETTE for creating tests for self-assessment (Guzmán \& Conejo, 2005), AITS that uses AI techniques (Hatzilygeroudis, Koutsojannis, Papavlasopoulos, \& J., 2006), system that uses AI agent technology (Song, Chen, \& Gao, 2011), while some testing system are compared in (Danieliené \& Telešius, 2008).

From many research results the true potential of CAT is evident. It provides valid knowledge assessment and teach student if needed. If adaptive e-test system recognizes some misunderstandings, weaknesses or pitfalls in student's answers then it selects new path of questions where student will be challenged to improve or correct his/her answers according to learning by assessment paradigm. It usually starts with a question of medium difficulty, while the questions path can be determined on-the-fly or can be predetermined (Cheng, Rodrigez, $\&$ Basu, 2009). Final grading is determined based on the answers in the questions path. CAT theory ensures that the obtained student knowledge estimations do not vary in terms of items used in the estimation process (Danieliené \& Telešius, 2008).

In the nineties we have created "Model of application of computer in education" (Gerlič, 1999) and one of the topics was Expert educational systems (EES). CATs use similar techniques as EES but the aim is different. When we observe intelligent computer aided education in 
PROBLEMS

OF EDUCATION

IN THE $21^{\text {st }}$ CENTURY

Volume 46, 2012

details we can see that differences in the tests and education are actually blurred. If we present knowledge with the network in the education we want students to visit all paths but in test we want students to find individual paths in limited amount of time.

\section{Designing CATs}

To prepare adaptive test teacher needs to prepare a blueprint of possible questions/ answers and state transition diagram. At least two different structures can be used: decision tree (Nančovska Šerbec, Žerovnik, \& Rugelj, 2011) or state transition diagram. A modified State Transition Diagram from UML (Unified Modeling Language) was used to be friendlier for general users - teachers (Figure 1). Therefore start sign and stop sign were omitted since reader can easily comprehend that. Colored rounded rectangular were used to indicate meta-questions and the rounded rectangular for real questions. Rectangular on the line is used for transition's condition. The rectangular with multiple questions represent the questions' set. Questions from the set can be chosen arbitrary and can be of any traditional e-test type. With this approach a focus is set on the knowledge evaluation paths. Grading can be omitted when building the test structure. If decision tree are used the paths and grading are built at the same time. Such process increase complexity and potential errors.

The best knowledge evaluation would be if students would present entire knowledge about the tested topic. Since there is not enough time teachers often compromise and ask only few questions and assess knowledge based on these questions. Teachers know these processes very well and understand them completely. Some teachers select questions from their inspiration but others prepare random questions on pick-up lists and enable students to choose the questions. Questions are usually broader and cover one or more topic of entire knowledge of course. If student gives suitable answers and show knowledge about that topic he/she receive grade. But if answers raise suspicion into student knowledge then additional questions (more elaborate and precise) are required to grade student. Every teacher is familiar with this process. Therefore this principle is applied in the design process of adaptive computer tests.

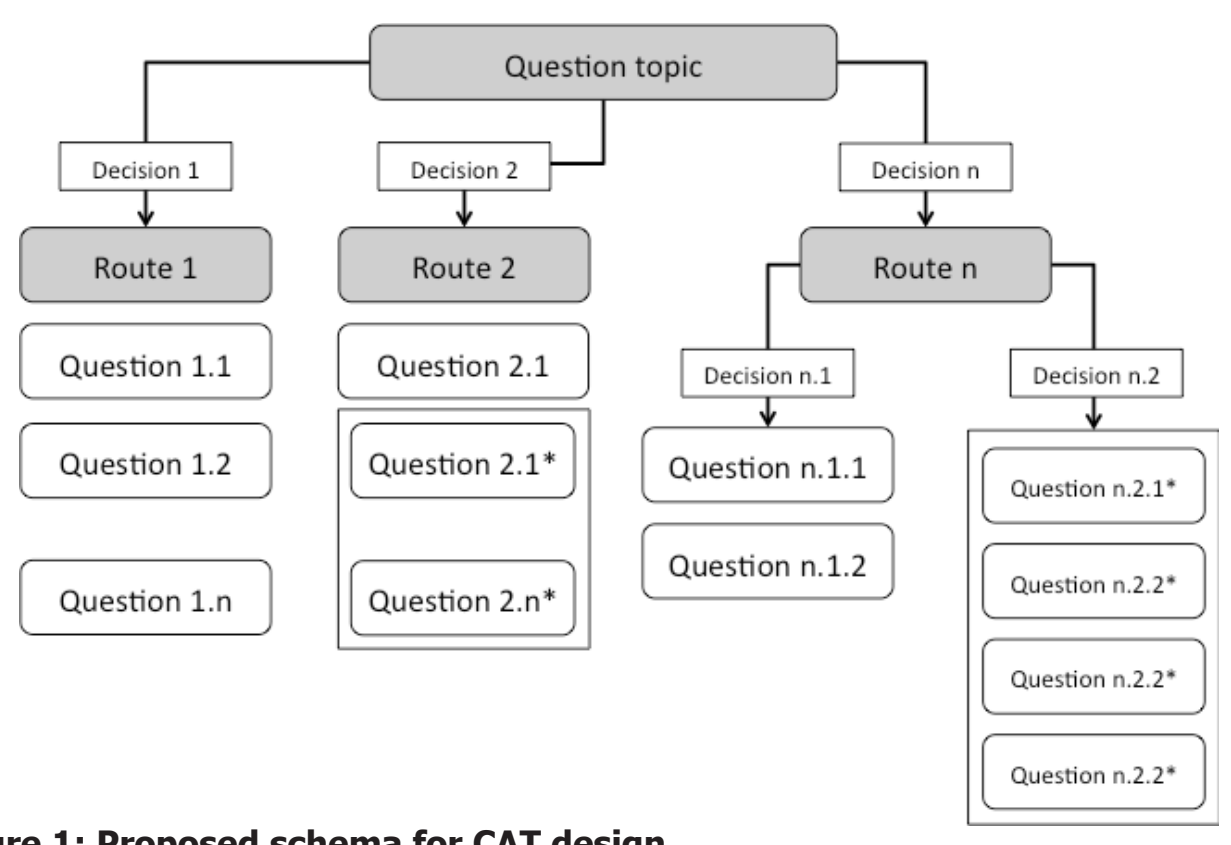

Figure 1: Proposed schema for CAT design. 
From the initial point (question topic) multiple routes can be used. Therefore student just picks one of them and according to the selected route questions that go with this route are evaluated. From the Figure 1we see that student can get mandatory question $(1.1-1 . n)$ or one mandatory question and elective questions $\left(2.1,2.1 *-2 . n^{*}\right)$ or can go to the lower decision level (decision n.1, n.2). This schematic approach is just transformation between what teachers ordinarily do and CAT system. Even grading is simple. Each route has maximum numbers of points and student's point are summed and compared to the maximum number of points.

grade $=\frac{\sum_{i=1}^{n} s_{i}}{\sum_{i=1}^{n} q_{i}}$

Where:

$$
\begin{array}{ll}
i & \text { index on the question. } \\
n & \text { number of question along the selected route. } \\
s_{i} & \text { student achievement on question } i . \\
q_{i} & \text { number of points on question } i .
\end{array}
$$

There are still unresolved ambiguities how to achieve back stepping on the selected route when users feel that corrections of previous answers are needed. At least two approaches can be used: (1) student cannot go back or (2) if student goes back and make change the system forget its subsequent answers. A debate is still open about grading upon students partial path completion.

For easier understanding example "how to upgrade your computer?" was prepared (Figure 2). In general there are three ways to improve computer. The option to buy another computer was dismissed since it would not provide any valuable results. Students can pick three answers in the first question (regarded as paths for later assessments): upgrade RAM, hard drive, or processor. If he/she decides to upgrade RAM then his/her decision is tested with the questions "How much RAM he/she wants to add", "*What operation system he/she has", "What is his/her current RAM configuration and what is his/her RAM speed". Not all the questions have to be asked but cascade question to check student's understanding are available (e.g. it is useless to upgrade RAM over 4 gigabytes if computer has 32 bit operating system). The schema shows that the question "How much RAM he/she wants to add" has subsequent question "What operation system he/she has". If desired questions can be subdivide into more details.

The second option, upgrading disk, can be fulfilled with two types of disk (magnetic or SSD - solid state disk). If student decides to change magnetic disk in his/her computer he/she is going to get three questions: what size of disk he/she wants to have, what speed of new disk he/she has in mind, and which technology (referred to type PATA and DMA types or SATA and subtypes) is on his/her mind. Each question can have right and wrong answers and the combination of answers from all three questions can be valid or not. It therefore may happen that answers to each question are true but combinations are not. On the other hand if he/she decides to use SSD disk only two additional questions will be asked: the size of SSD, and why he/she will use this disk. For example, it is known that Windows XP can be squeezed on 4 GB disk but Windows 7 requires around $18 \mathrm{~GB}$. We could also add another question in this topic about the price.

The third option to upgrade processor is prepared in similar fashion. 
PROBLEMS

OF EDUCATION

IN THE $21^{\text {st }}$ CENTURY

Volume 46, 2012

90
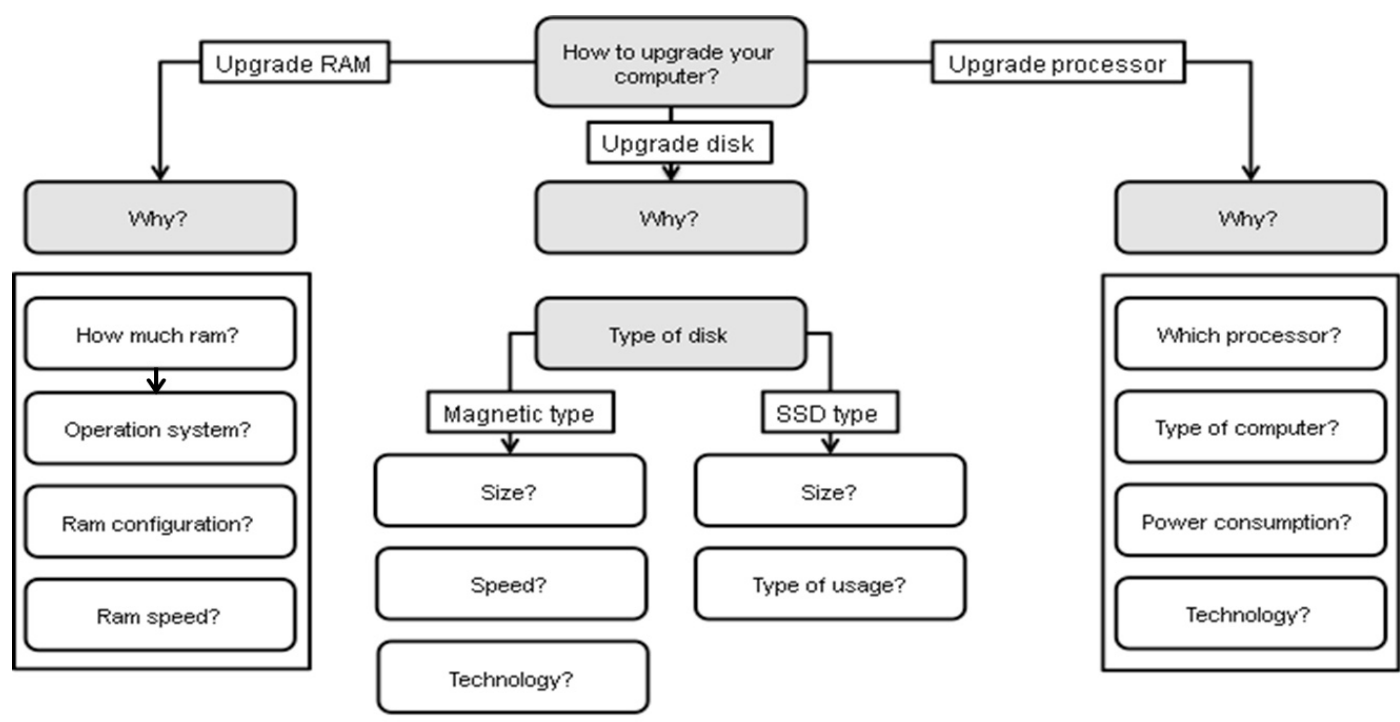

Conclusion

Figure 2: Schema - example - computer upgrade.

With the proposed design process for smart testing some examples were made. Some teachers with high level of enthusiasm have grasped the idea quickly but some dismiss it entirely. Especially old teachers would not like to change their proven assessment principles (face-to-face assessment). Younger teachers and assistants were much keener to adopt this since they discover positive side-effect of this process. Based on such schema they prepare better elearning materials. Only the time will tell if this will become a blueprint for better e-learning and e-testing preparation or it is going to be upgraded and incorporate into another better proposal.

\section{Conclusion}

Research and development is never a straightforward process. Even if e-learning materials are still far from being good teachers do not demand their improvements. In house training shows that most desirable topics in e-learning are e-tests. Reasons are clear and expected but the rush may not provide satisfactory results. E-tests require a mental change from traditional tests. Not all teachers have the ability to switch immediately and some training and support will be required. Persons responsible for transition from traditional test to e-test must highlight the problems of e-tests and prevent teachers to use inappropriate concept from traditional test (fill-in blanks) too often. The poor results may increase frustration of students beyond acceptable level. Based on gained experiences several years will pass before application of CAT in Slovenia's LMSs. Authoring tool that enables conditional testing are available but they are not cheap (e.g. Articulate Quiz Maker). The technology used in these tools is Flash and is not supported on low powered portable devices which gain increased users' popularity. Even graphical tool that would support development of conditional routed e-test is not available. Using flow charts building blocks would be feasible but teachers are not familiar with them. Conditional diamond from flow chart is much spatial demanding and has little usable space for text. The proposed scheme is far from perfect but it is a start and PowerPoint can be used for its design. Prediction therefore is that in the near future a GUI (graphical user interface) will be developed to support CAT in most used LMSs in more natural way. 


\section{References}

Barra, M., Iannaccone, A., Palmieri, G., \& Scarano, V. (2002). Test C++: An Adaptive Training System on the Internet. ISCC'02. Taormina- Giardini Naxos, Italy.

Basu, A., Cheng, I., Prasad, M., \& Rao, G. (2007). Multimedia Adaptive Computer based Testing: An Overview. ICME 2007. Beijing.

BBC (2012, April 23). BBC. Retrieved April 30, 2012, from News Technology: http://www.bbc.com/ news/technology-17811557

Chen, J., \& Wang, L. (2010). Computerized Adaptive Testing: A New Trend in Language Testing. International Conference on Artificial Intelligence and Education (ICAIE). Xi'an, China. Retrieved from http://ieeexplore.ieee.org/stamp/stamp.jsp?arnumber $=05641509$

Chen, S., \& Zhang, J. (2008). Ability Assessment based on CAT in Adaptive Learning System. International Workshop on Education Technology and Training \& International Workshop on Geoscience and Remote Sensing. Shanghai, China.

Cheng, I., Rodrigez, S., \& Basu, A. (2009). Multimedia and Games incorporating Student Modeling for Education. International Workshop on Technology for Education (T4E). Bangalode.

Chua Abdullah, S., \& Cooley, R. E. (2002). Using Simulated Students to Evaluate an Adaptive Testing System. International Conference on Computers in Education. Auckland, New Zealand.

Costello, R., \& Mundy, D. P. (2009). The Adaptive Intelligent Personalised Learning Environment. 9th IEEE International Conference on Advanced Learning Technologies.

Danieliené, R., \& Telešius, E. (2008). Analysis of Computer-Based Testing Systems. HSI 2008. Krakow, Poland.

Gerlič, I. (1999). Models of computer application in education. Association for the Advancement of Computing in Education. San Antonio, Texas.

Gerlič, I. (2000). Sodobna informacijska tehnologija v izobraževanju. Ljubljana: DZS.

Gerlič, I., Bratina, T., Veček, N., \& Pungartnik, T. (2011). Stanje in trendi uporabe informacijsko komunikacijske tehnologije (IKT) v slovenskih osnovnih šolah. Maribor: University of Maribor, Faculty of Natural Sciences and Mathematics.

Guzmán, E., \& Conejo, R. (2005). Self-Assesment in a Feasible, Adaptive Web-Based Testing System. IEEE Transactions on Education, 48 (4).

Hatzilygeroudis, I., Koutsojannis, C., Papavlasopoulos, C., \& Prentzas, J. (2006). Knowledge-based Adaptive Assessment in a Web-Based Intelligent Educational System. 6th Int. Conference on Advanced Learning Technologies (ICALT'06). Kerkrade, The Netherlands.

Lord, F. M. (1980). Applications of item response theory to practical testing problems. Hillsdale, NJ: Lawrence Erlbaum Associates.

Nančovska Šerbec, I., Žerovnik, A., \& Rugelj, J. (2011). Adaptive assessment based on decision trees and decision rule. CSEDU 2011 - Proceedings of the 3rd International Conference on Computer Supported Education. Noordwijkerhout, Netherlands.

Parshall, C. G., Spray, J. A., Kalohn, J. C., \& Davey, T. (2002). Considerations in Computer-Based Testing. New York: Springer.

Repnik, R., Krašna, M., \& Kaučič, B. (2012). E-learning in the modern curriculum development. In $E$ learning / book 5 (p. (In print)). Rijeka: InTech.

Song, J., Chen, W., \& Gao, E. (2011). The Adaptive On-line Exam System based on Agent. International Conference on Future Computer Science and Education. Xi'an, China. 
PROBLEMS

OF EDUCATION

IN THE $21^{\text {st }}$ CENTURY

volume 46,2012
Advised by Boris Aberšek, University of Maribor, Slovenia

Received: May 14, 2012

Accepted: August 06, 2012

\begin{tabular}{|ll|} 
Marjan Krašna & $\begin{array}{l}\text { PhD., Professor, University of Maribor, Faculty of Arts, Department of Pedagogy, } \\
\text { Maribor, Slovenia. } \\
\text { E-mail: marjan.krasna@uni-mb.si }\end{array}$ \\
\hline Tomaž Bratina & $\begin{array}{l}\text { Assistant, University of Maribor, Faculty of Education, Department for Primary Educa- } \\
\text { tion, Maribor, Slovenia. } \\
\text { E-mail: tomaz.bratina@uni-mb.si }\end{array}$ \\
\hline Branko Kaučič & $\begin{array}{l}\text { PhD, Associate Professor, University of Ljubljana, Faculty of Education, Department of } \\
\text { Mathematics and Computer Science, Slovenia. } \\
\text { E-mail: branko.kaucic@pef.uni-li.si }\end{array}$ \\
\hline
\end{tabular}

